\title{
The effects of sibling reproduction in the African striped mouse
}

\begin{abstract}
Neville PILLAY
Pillay N. 1999. The effects of sibling reproduction in the African striped mouse. Acta Theriologica 44: 291-298.

Sibling reproduction was studied in a captive population of the African striped mouse Rhabdomys pumilio (Sparrman, 1784) to establish the occurrence of inbreeding and whether early association prevents later matings. Sibling and nonsibling pairs were established by pairing animals at weaning ( 16 days), 30 , and 60 days old. The reproductive success of weaning pairs (regardless of genetic relationship) and 30- and 60-day sibling pairs was poorer than that of nonsibling pairs. Inbreeding depression was indicated by high pre-weaning mortality and smaller mass of inbred compared to outbred litters. When pairings were made between sexually mature siblings of consecutive litters that had made brief contact previously, sibling pairs had similar reproductive performance compared to control pairs, but had significantly smaller litter sizes. It appears that incestuous matings in $R$. pumilio result in inbreeding depression, and that mating between kin or non-kin is prevented by prior association.

Environmental Physiological Studies Research (ESPR) Programme, Department of Zoology, University of the Witwatersrand, Private Bag 3, WITS 2050, Republic of South Africa, e-mail: NevilleP@gecko.biol.wits.ac.za

Key words: Rhabdomys pumilio, sibling recognition, incest, inbreeding avoidance, reproduction
\end{abstract}

\section{Introduction}

Mating between closely related relatives is rare in nature (Ralls et al. 1986, Bollinger et al. 1991). This may be to avoid inbreeding depression, mainly due to increased homozygosity and expression of deleterious alleles (Ralls and Ballou 1982). Selection should act against inbreeding, which reduces reproductive fitness. Inbreeding may be favoured, however, under certain circumstances, if the costs of avoiding inbreeding outweigh the benefits (Partridge 1983).

Matings between close relatives may be prevented as a result of spatio-temporal separation of near relatives (eg, by dispersal; Keane 1990, Hoogland 1995); dispersal may have other functions than bringing about inbreeding avoidance, however (Moore and Ali 1984, Anderson 1989). In areas of contact, inbreeding is discouraged among relatives by several means. For example, incestuous breeding is prevented by postponing reproductive events when in contact with kin, as reported in some rodent species (Hoogland 1995). Moreover, individuals may choose to mate with non-kin rather than kin (Partridge 1983, Barnard and Aldhous 1991). 
Kin recognition between potential mates is one of the mechanisms used to prevent inbreeding (Batzli et al. 1977, Blaustein 1983, Partridge 1983, Barnard and Aldhous 1991). There are four proximate mechanisms of kin recognition: (1) spatial distribution; (2) association; (3) phenotype matching; and (4) recognition alleles (see Holmes and Sherman 1982 for a detailed review of each). The most common of the four mechanisms is recognition by means of prior association. Here, an animal learns the characteristics of individuals with which it interacts socially during early life (Holmes and Sherman 1982, Halpin 1991).

The African striped mouse Rhabdomys pumilio (Sparrman, 1784) is a murid rodent. It has a wide distribution south of the Sahara (Skinner and Smithers 1990), although its distribution is patchy in east Africa and in the northern limits of its range (De Graaff 1981). In southern Africa, adult males and females are of similar size, weighing a mean of $43.1 \mathrm{~g}$ and $41.4 \mathrm{~g}$ respectively.

Previous studies of dispersal in the striped mouse indicate two important phenomena. Firstly, Willan (1982) postulated that there is group dispersal in free-living $R$. pumilio, and that there is high sibling affinity from weaning (16 days) until about 30 days of age. Secondly, dispersal occurs as a two-phase strategy, whereby newly weaned young reside in the maternal territory until replaced by the next litter (Brooks 1982, Willan and Meester 1989). Also, Willan (1982) reported possible contact between siblings of consecutive litters.

On the basis of these observations, it is hypothesised that the early association between siblings of the same and consecutive litters would prevent inbreeding. To test this hypothesis, two experiments were undertaken. In the first experiment, a comparison was made of the reproductive performance of sibling and nonsibling pairs established before and after sexual maturity. In the second experiment, pairings were established between siblings of consecutive litters (ie first and second litters). These siblings made brief contact (ie for 3-4 days) when the first litter was weaned, simulating the two-phase dispersal strategy of $R$. pumilio (above).

\section{Material and methods}

Animals used in the study were $\mathrm{F}_{1}$ and $\mathrm{F}_{2}$ generation progeny of wild-caught parents originating from Alice, Eastern Cape Province ( $32^{\circ} 48^{\prime} \mathrm{S}$; $\left.26^{\circ} 52^{\prime} \mathrm{E}\right)$, South Africa. Striped mice were housed in a room with environmental control (light regime of $14 \mathrm{~L}: 10 \mathrm{D}$, lights on at $05 \mathrm{~h} 00 ; 20-24^{0} \mathrm{C} ; 30-60 \% \mathrm{rH}$ ). Breeding pairs were established in $400 \times 250 \times 120 \mathrm{~mm}$ Lab-o-tec ${ }^{\mathrm{R}}$ cages. Coarse wood shavings were provided as litter, and animals used hay as nesting material. Epol ${ }^{R}$ mouse cubes, Epol ${ }^{R}$ dog cubes, and water were provided ad libitum and apple was provided weekly.

\section{Experiment 1}

Sibling (inbred) and nonsibling (outbred) pairs were established at weaning (16-18 days of age), 30-35 days (denoted as 30-day pairs) and at onset of sexual maturity (ie, 60-64 days of age; denoted as 60-day pairs). Individuals used in 30 and 60-day pairs were weaned at 16 days of age and maintained with littermates in same-sex groups until they were used in experiments. Whenever possible, experimental animals were chosen from litters that had two or more males and females. From each 
litter, two individuals were randomly selected and one sibling pair was formed; other siblings were paired with nonsiblings.

Immediately after parturition, fathers were removed from the cage and housed elsewhere. Pairs that had not produced after 110 days (weaning pairs), 90 days (30-day pairs) and 40 days (60-day pairs) were separated. Since pairs were established using individuals of different ages, pairs were separated at different times to allow animals to attain sexual maturity and gestation; free-living and captive $R$. pumilio mature at approximately 60 days and have a mean gestation of 25.4 days (Brooks 1982, Skinner and Smithers 1990), so that individuals in all pairs had sufficient time to attain maturity and produce offspring. In order to test for fertility, $50-60 \%$ of the individuals in each mating category that did not reproduce within the allocated time (above) were paired a month after separation with unfamiliar mates of known fertility.

The reproductive performance of the different pairings (sibling and non sibling weaning, 30- and 60-day pairs) was compared by recording the proportion of pairs that reproduced, latency from pairing to parturition, litter size at birth, sex ratio at birth, and pre-weaning mortality.

The postnatal growth of some litters was studied by weighing young daily from birth to 16 days of age, and weekly thereafter to an age of 10 weeks. At weaning, young were housed with littermates in same-sex groups. Comparisons were made of the growth of litters produced by inbred and outbred pairs by age category of the parents (eg litters of 30-day sibling vs litters of 30-day nonsibling pairs).

\section{Experiment 2}

In the second experiment, pairings were established between siblings of consecutive litters (ie same parents but different litters). Rhabdomys pumilio displays post-partum oestrus (Brooks 1982), so that consecutive litters can make contact in captivity. The first litter was removed (mean age at removal = 28 days) from the breeding cage 3-4 days after the birth of the next litter, and housed in same-sex groups in a different room. Therefore, individuals of the first litter briefly associated with their younger siblings, while the second litter had the opportunity to make auditory, olfactory and tactile contact with their older siblings. At pairing, all individuals were sexually mature, and the mean age difference between individuals in these pairs was $120( \pm 5.4)$ days. Control pairs were established between unrelated individuals with a mean age difference of $114( \pm 3.2)$ days. All individuals used in these experiments were reproductively naive at pairing. I compared the breeding of test and control pairs using the same reproductive parameters described in experiment 1 (above).

Statistical analyses used for breeding data included $\chi^{2}$ (comparison of proportions, goodness of fit), one-way ANOVA, and Student's $t$-tests, and comparison of growth data was done using the Mann-Whitney $U$-test (Zar 1996). Mean values are given with $1 \mathrm{SE}$ throughout.

\section{Results}

\section{Experiment 1}

Reproductive success (production of offspring) was proportionately greater in nonsibling than sibling pairs $\left(\chi^{2}=61.23, \mathrm{df}=5, p<0.001\right.$; Table 1$)$. Weaning sibling pairs never produced offspring, while weaning outbred pairs also showed reduced success, with only $20 \%$ of pairs producing litters (Table 1 ). The low success recorded in the 30 -day sibling pairs $(33.3 \%$; Table 1 ) was due to the fact that more than half of the males attacked and wounded their mates, necessitating separation of ten 30-day sibling pairs. In contrast, $90.9 \%$ of 30-day nonsibling pairs produced offspring. Similarly, fewer 60 -day sibling pairs $(45 \%)$ produced litters compared to same-age nonsibling pairs (95\% Table 1). 
Table 1. Summary of the reproductive performance of the six pairings indicated. Sex ratio Male:Female; SE given in brackets. ${ }^{1}$ Success - percentage of the total pairs that produced offspring.

\begin{tabular}{|c|c|c|c|c|c|c|}
\hline \multirow{2}{*}{ Parameter } & \multicolumn{3}{|c|}{ Sibling pairs } & \multicolumn{3}{|c|}{ Nonsibling pairs } \\
\hline & Weaning & 30-day & 60-day & Weaning & 30-day & 60-day \\
\hline$n$ & 21 & 18 & 20 & 20 & 22 & 20 \\
\hline Success $(\%)^{1}$ & 0 & 33.3 & 45 & 20 & 90.9 & 95 \\
\hline Mean number of days to litter & - & $\begin{array}{l}41.3 \\
(3.7)\end{array}$ & $\begin{array}{c}27.2 \\
(0.9)\end{array}$ & $\begin{array}{l}93.3 \\
(1.4)\end{array}$ & $\begin{array}{l}34.1 \\
(2.2)\end{array}$ & $\begin{array}{c}26.6 \\
(0.6)\end{array}$ \\
\hline Mean litter size & - & $\begin{array}{c}5.8 \\
(0.9)\end{array}$ & $\begin{array}{c}5.6 \\
(0.4)\end{array}$ & $\begin{array}{c}6.0 \\
(0.7)\end{array}$ & $\begin{array}{c}6.1 \\
(0.5)\end{array}$ & $\begin{array}{c}7.7 \\
(0.4)\end{array}$ \\
\hline Sex ratio & - & $18: 17$ & $36: 39$ & $12: 12$ & $63: 58$ & $71: 76$ \\
\hline Pre-weaning mortality (\%) & - & 71.4 & 15.3 & 8.3 & 5.5 & 6.3 \\
\hline
\end{tabular}

Failure of pairs to produce litters was most likely not because of infertile individuals, since 66 of 69 (94\%) individuals that failed to produce offspring in the breeding trails, reproduced successfully when re-paired with unfamiliar mates.

The interval between pairing and parturition was compared between sibling and nonsibling pairs for both 30-day pairs and for 60-day pairs. Neither 30-day $\left(t_{24}=\right.$ $1.65, p>0.05)$ nor 60-day $\left(t_{26}=0.64, p>0.05\right)$ pairs differed significantly in the time taken to produce offspring.

One way ANOVA with an a posteriori Duncan's multiple range test were used to statistically compare litter sizes of all mating categories. Mean litter size was significantly higher in 60-day nonsibling pairs than in other pairs $\left(F_{4,57}=2.97, p<\right.$ 0.05 ; Table 1).

In no mating category did the sex ratio at birth differ significantly from parity (Table 1). Pre-weaning mortality differed significantly across all pairings $\left(\chi^{2}=\right.$ $74.33, \mathrm{df}=4, \mathrm{p}<0.001$ ), and was extremely common in offspring of 30-day inbred pairs (Table 1). All inbred and $<20 \%$ outbred young that died during the study were wounded or partially consumed, suggesting that maternal infanticide may have been the cause of death.

The growth rate in respect of body mass of inbred and outbred offspring are shown in Fig. 1. Outbred young of 30-day pairs were heavier than their inbred counterparts from 0 to 3 weeks of age (Fig. 1a), but growth of both types of offspring were similar for the remainder of the study. Offspring of 60-day sibling and nonsibling pairs had similar growth patterns, although outbred young were heavier than inbred ones on week 3 (Fig. 1b).

\section{Experiment 2}

Although the breeding success of siblings from consecutive litters (21 of 25 pairs) was similar to that of control pairs (27 of 30 pairs; $\chi^{2}=0.65, p>0.05$ ), the litter size of sibling pairs was significantly smaller than control pairs $(5.6 \pm 2.6$ vs 

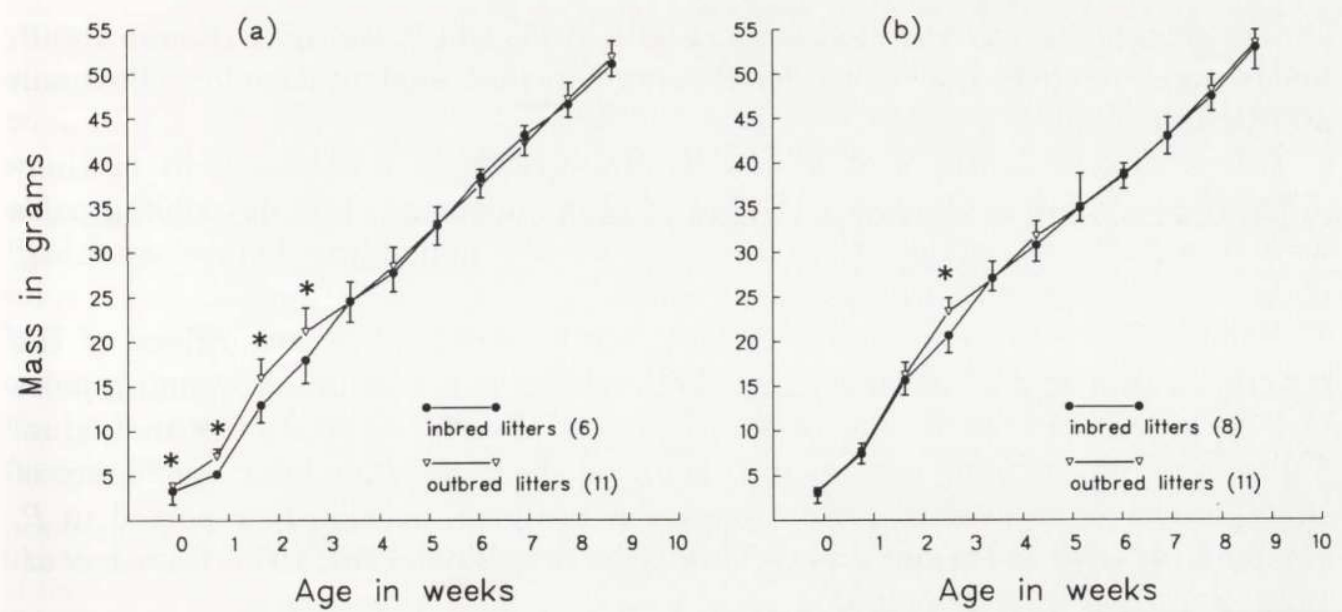

Fig. 1. Mean mass of inbred and outbred offspring resulting from (a) 30-day and (b) 60-day pairs over 10 weeks. Vertical bars $=1 \mathrm{SE}$ above or below the mean. Sample size given in brackets, and indicates the number of litters weighed. ${ }^{*}$ - significantly different mean values (Mann-Whitney $U$-test).

$\left.7.1 \pm 2.2 ; t_{46}=2.16, p<0.05\right)$. Sibling and control pairs took a similar time to produce litters $\left(27.0 \pm 5.6\right.$ vs $26.4 \pm 3.2$ days; $\left.t_{46}=1.169, p>0.05\right)$ respectively, and the percentage pre-weaning mortality of inbred young (9.5\%) was not significantly different than that of outbred young $\left(6.2 \% ; \chi^{2}=0.65, p>0.05\right)$. A sex ratio of $41: 33$ (male:female) was recorded at birth for sibling pairs and 93:99 for control pairs; neither differed significantly from unity.

\section{Discussion}

The reproductive success (as measured by the number of pairs producing litters) of sibling pairs was generally lower than nonsibling pairs in experiment 1 , but reproductive success was equally high in both sibling and control pairs in experiment 2. In both experiments, litter size was smaller in siblings than nonsiblings, suggesting inbreeding depression in incestuous matings.

High levels of aggression between brother and sister resulted in damaging fights, necessitating separation of many 30 -day sibling pairs. Such aggression was absent in 30-day nonsibling pairs, suggesting that the age at pairing did not contribute to comparatively high aggression in sibling pairs. While sibling aggression did not allow for mating, the reasons for aggression in 30-day sibling pairs are not understood.

Inbreeding reduces reproductive fitness because, among other factors (eg litter size; above), inbred offspring are inviable (Ralls et al. 1986). The reduced litter size of sibling pairs and high pre-weaning mortality of some inbred young suggest a reduction in fitness. Reduced litter size of sibling matings has been shown also in 
sibling pairs of Peromyscus maniculatus (Hill 1974) and P. leucopus (Keane 1990), and is suggested to be due to post-fertilization and post-implantation loss (Bowman and Roberts 1958).

Infanticide by mothers of inbred litters suggests a breakdown in mother-offspring recognition (Harper 1981). In addition, offspring of 30-day sibling pairs were significantly smaller than those of 30 -day nonsibling before weaning, potentially contributing to their being killed.

Early pairing (at weaning) interferes with reproduction, regardless of the genetic relationship of pairings, since both sibling and nonsibling weaning pairs had the lowest reproductive success in the study. Clearly, association of individual $R$. pumilio from weaning reduces the likelihood of reproduction later. Avoidance of sibling matings because of prior association has been previously reported in $P$. maniculatus (Hill 1974) and three Microtus species (Batzli et al. 1977, Gavish et al. 1984, Boyd and Blaustein 1985).

The exact mechanisms hindering reproduction in sibling pairs in experiment 1 is not known. One or more of the following mechanisms may be implicated: delayed sexual maturation, impaired copulatory behaviour, and intra-uterine loss of embryos (Hill 1974). Moreover, the reviews by Partridge (1983) and Barnard and Aldhous (1991) indicate that mate choice may be influenced by the degree of relatedness of potential mates, so that inbreeding or outbreeding occurs depending on the species studied. It is possible that, in sibling pairs of $R$. pumilio, one or both sexes may have been reluctant to mate because of behavioural barriers to inbreeding (Partridge 1983).

Kin recognition appeared to diminish with time, because the reproductive success of sibling pairs improved with a longer period since separation at weaning (ie increasing reproductive success from 30-day to 60-day sibling pairs). Separation has also been shown to increase the incidence of sibling reproductive success in Microtus ochrogaster (Gavish et al. 1984). In addition, the brief association of siblings of consecutive litters in the second experiment failed to prevent sibling matings. Thus, the results of experiment 2 support those of the first experiment in that siblings from different litters did not have the opportunity to associate and learn the cues necessary to recognise kin (Halpin 1991). Clearly, R. pumilio identifies kin because of association during rearing.

Errors in recognition reduce the fitness of those $R$. pumilio individuals mating with kin or those that do not outbreed, since sibling matings result in a waste of gametes and a reduction in fitness. However, errors in kin recognition may not occur in free-living populations because of the social and population biology of the taxon.

Breeding female striped mice are intrasexually territorial, maintaining discrete, non overlapping territories in nature (Willan 1982). There is high incidence of infanticide by females of unfamiliar weanlings (Marais 1974) which may be the underlying reason for female territoriality (Willan 1982). The two-phase dispersal strategy of weaned striped mice young may in turn function to delay dispersal until 
young are able to fend for themselves. The following scenario is therefore plausible: siblings will disperse from the maternal territory only at 30-40 days of age (ie weaning at 16 days $+15-25$ days before the next litter is weaned). Similar age non-kin are unlikely to meet before they disperse. If this is the case, the results obtained in the present study suggest a reduced incidence of sibling mating and the likelihood of nonsibling matings at maturity. In addition, delaying dispersal may allow siblings of consecutive litters to associate. Captive females with neonates are highly tolerant of their weaned offspring of the previous litter, suggesting that contact between consecutive litters may occur more frequently than was the case in the present study. Clearly, all the hypotheses raised here require testing in free-living populations.

Acknowledgements: Thanks to Rod Baxter for providing wild-caught animals, Gerda du Preez for technical assistance, two anonymous referees for comments, and the University Research Committee of the University of the Witwatersrand for financial support. Animal ethics clearance number: AESC $96 / 22 / 2$ a.

\section{References}

Anderson P. K. 1989. Dispersal in rodents: a resident fitness hypothesis. Special publication No. 9. The American Society of Mammalogists: 1-141.

Barnard C. J. and Aldhous P. 1991. Kinship, kin discrimination and mate choice. [In: Kin recognition. P. G. Hepper, ed]. Cambridge University Press, Cambridge: 125-147.

Batzli G. O., Getz L. L. and Hurley S. S. 1977. Suppression of growth and reproduction of microtine rodents by social factors. Journal of Mammalogy 58: 583-591.

Blaustein A. R. 1983. Kin recognition mechanisms: phenotypic matching or recognition alleles? The American Naturalist 121: 749- 754.

Bollinger E. K., Harper S. J., Kramer J. M. and Barrett G.W. 1991. Avoidance of inbreeding in the meadow vole (Microtus pennsylvanicus). Journal of Mammalogy 72: 419-421.

Bowman J. C. and Roberts R. C. 1958. Embryonic mortality in relation to ovulation rate in the house mouse. Journal of Experimental Biology 35: 138-143.

Boyd S. K. and Blaustein A. R. 1985. Familiarity and inbreeding avoidance in the gray-tailed vole (Microtus canicaudus). Journal of Mammalogy 66: 348- 352.

Brooks P. M. 1982. Aspects of the reproduction, growth and development of the four-striped, Rhabdomys pumilio (Sparrman, 1784). Mammalia 46: 53- 63.

De Graaff G. 1981. The rodents of southern Africa. Butterworths, Durban: 1-266.

Gavish L. H., Hoffman J. E. and Getz L. L. 1984. Sibling recognition in the prairie vole, Microtus ochrogaster. Animal Behaviour 32: 362-366.

Hill J. L. 1974. Peromyscus: effect of early pairing on reproduction. Science 186: 1042-1044.

Halpin Z. T. 1991. Kin recognition cues of vertebrates. [In: Kin recognition. P. G. Hepper, ed]. Cambridge University Press, Cambridge: 220-258.

Harper L. V. 1981. Offspring effects upon parents. [In: Parental care in mammals. D. J. Gubernick and P. H. Klopper, eds]. Plenum Press, New York: 117-177.

Holmes W. G. and Sherman P. W. 1982. The ontogeny of kin recognition in two species of ground squirrels. American Zoology 22: 491-517.

Hoogland J. L. 1995. The black-tailed prairie dog: social life of a burrowing mammal. The University of Chicago Press, Chicago: 1-557.

Keane B. 1990. Dispersal and inbreeding avoidance in the white-footed mouse, Peromyscus leucopus. Animal Behaviour 40: 143-152. 
Marais F. J. 1974. The behaviour and population dynamics of a confined colony of striped mice (Rhabdomys pumilio). M Sc thesis, University of Pretoria, Pretoria: 1-200.

Moore J. and Ali R. 1984. Are dispersal and inbreeding avoidance related? Animal Behaviour 32: 94-112.

Partridge L. 1983. Non-random mating and offspring fitness. [In: Mate choice. P. Bateson, ed]. Cambridge University Press, Cambridge: 227-255.

Ralls K. and Ballou J. 1982. Effects of inbreeding on infant mortality in captive primates. International Journal of Primatology 3: 491-505.

Ralls K., Brugger K. and Ballou J. 1986. Inbreeding and juvenile mortality in small populations of ungulates. Science 206: 1101-1103.

Skinner J. D. and Smithers R. H. N. 1990. The mammals of the southern African subregion. University of Pretoria, Pretoria: 1-771

Willan K. 1982. Social ecology of Otomys irroratus, Rhabdomys pumilio and Praomys natalensis. $\mathrm{Ph} \mathrm{D}$ thesis, University of Natal, Pietermaritzburg: 1-294.

Willan K. and Meester J. 1989. Life history tactics of southern African Mastomys natalensis, Otomys irroratus and Rhabdomys pumilio (Mammalia, Rodentia). [In: Alternative life history styles of animals. M. N. Bruton, ed]. Kluwer, Dordrecht: 421-439.

Zar J. H. 1996. Biostatistical analysis. 3rd edition. Prentice Hall, Inc., London: 1-662.

Received 5 May 1998, accepted 1 October 1998. 